\section{The effects of air pollution on respiratory health in susceptible populations: a multilevel study in Bucaramanga, Colombia}

\author{
Efectos de la contaminación atmosférica \\ en la salud respiratoria de población susceptible: \\ un estudio multinivel en Bucaramanga, Colombia
}

\author{
1 Universidad Industrial de \\ Santander, Bucaramanga, \\ Colombia. \\ 2 Observatorio de Salud \\ Pública de Santander, \\ Fundación Oftalmológica de \\ Santander, Bucaramanga, \\ Colombia. \\ 3 Corporación Autónoma \\ Regional para la Defensa de \\ la Meseta de Bucaramanga, \\ Bucaramanga, Colombia. \\ Correspondence \\ L. A. Rodriguez-Villamizar \\ Universidad Industrial de \\ Santander. \\ Carrera 32 no. 29-31, piso 3, \\ Bucaramanga, Santander-7, \\ Colombia. \\ laurarovi78@gmail.com
}

\begin{abstract}
We conducted a cohort study to investigate the association between exposure to three different levels of outdoor air pollution and incidence of respiratory symptoms in a population with chronic cardiovascular and respiratory disease. We accompanied 756 participants for a period of six months through the maintenance of a daily record of symptoms and clinic visits. The symptoms with highest incidence rates were sneezing and hacking cough. Multivariate analysis showed that incidence of total symptoms was $60 \%$ and 74\% lower in areas with medium and low levels of pollution compared to areas with high levels of pollution. These results suggest that negative respiratory effects occur at concentrations of particulate matter PM10 > 60ug/ $/ \mathrm{m}^{3}$.
\end{abstract}

Respiratory Signs and Symptoms; Chronic Disease; Air Pollution; Population
Laura Andrea Rodriguez-Villamizar 1,2 Henry Castro-Ortiz 3

Juan Jose Rey-Serrano 2

\section{Introduction}

Air pollution is a well known environmental determinant of health, especially among urban populations ${ }^{1}$. This association is probably due to growing industrialization and an increase in the use of motor vehicles. The effects of this process have been shown not only in developed countries but also in small and large cities in the developing world 2 .

Several studies have demonstrated the association between air pollution and respiratory and cardiovascular diseases 3,4,5,6. Increased concentrations of particulate matter with an aerodynamic diameter of less than $10 \mu \mathrm{g} / \mathrm{m}^{3}$ (PM10) is associated with an acute increase in emergency room visits, hospital admissions, respiratory symptoms, mortality rate due to respiratory and cardiovascular disease and restricted activity days due to morbidity 7,8 .

Children and older or chronically sick individuals are most susceptible to the negative effects of air pollution 9,10. This finding is explained biologically by an immature or low immunological system response and particulate matter entering the respiratory system is expected to have a more acute respiratory effect in susceptible people 11.

Bucaramanga is a city with approximately 600,000 inhabitants located 980 meters above sea level in the northwest of Colombia. Average annual temperature is $22.1^{\circ} \mathrm{C}\left(18.8^{\circ} \mathrm{C}\right.$ to $\left.30^{\circ} \mathrm{C}\right)$ 
and average annual humidity is $83.9 \%$. The city's air quality monitoring network has shown PM10 concentrations that are higher than the locallyadjusted national limits 12 (maximum limit of $134 \mu \mathrm{g} / \mathrm{m}^{3} 24$ hours) and the international limits 13 (maximum limit of $150 \mu \mathrm{g} / \mathrm{m}^{3} 24$ hours) in some areas.

A recent study of children under seven years of age living in the city and exposed to high and low levels of PM10 concentrations did not find any association between exposure to PM10 and incidence of respiratory symptoms 14 . However, most of the children studied were healthy and it is not known whether exposure to different levels of PM10 has an adverse effect on the city's susceptible population considered as those individuals with a chronic cardiovascular or respiratory morbidity background.

The aim of this study was to analyze the effects of exposure to three different levels of air pollution, measured in PM10 concentrations, on the respiratory health of Bucaramanga's susceptible population.

\section{Materials and methods}

\section{Study design}

We conducted a prospective cohort study where exposure was considered to be air pollution levels measured in PM10 concentrations registered in the participants' area of residence and outcome is the incidence of respiratory symptoms. Air quality was measured by the air quality monitoring network of the Bucaramanga Agency for Environmental Protection. Three manual (Higvol Andersen Graseby) and three electronic instruments were used for this purpose at six points around the city (one in the north, south, east and west and two in the city center) before, during and after the study.

Before sampling, we defined three different categories of air pollution levels with the following mean PM10 concentrations: low $\left(<40 \mu \mathrm{g} / \mathrm{m}^{3}\right)$, medium (between 40 and $60 \mu \mathrm{g} / \mathrm{m}^{3}$ ) and high (> $\left.60 \mu \mathrm{g} / \mathrm{m}^{3}\right)$. However, for analysis purposes the neighborhoods were reclassified according to the PM10 concentration registered during the followup period using the same cut-off points.

Areas with high levels of pollution were identified in the city center (PM10 daily mean of $65 \mu \mathrm{g} / \mathrm{m}^{3}$ ) and south (PM10 daily mean of $83 \mu \mathrm{g} /$ $\mathrm{m}^{3}$ ), characterized by a high concentration of bus, motorcycle and commercial motor vehicle traffic. Areas with medium levels of pollution were found to be present in the north (PM10 daily mean of $52 \mu \mathrm{g} / \mathrm{m}^{3}$ ) and east (PM10 daily mean of
$48 \mu \mathrm{g} / \mathrm{m}^{3}$ ) of the city where traffic mainly consisted of motorcycles and, to a lesser extent, buses, taxis, motor vehicles and shoe-making machines in some houses. The west point of the city was considered as having a low level of pollution (PM10 daily mean of $35 \mu \mathrm{g} / \mathrm{m}^{3}$ ) and characterized by motorcycle and taxi traffic and a smaller presence of buses and motor vehicles and small scale commercial activity.

\section{Participants}

People of all age groups living around the six sites described above were contemplated. People with chronic cardiovascular or respiratory disease were included. However, people with neurological impairment or severe respiratory disease and using a partial or permanent oxygen supply were excluded. A sample size of 260 people per area (a total of 780 over the three areas) was calculated based on the following parameters: a power of $80 \%$, alpha 0.05 , a gap between higher and lower incidence of $10 \%$ and follow-up losses of up to $20 \%$. At the beginning of the study, eligible people were invited to participate and a standard questionnaire was administered to obtain the following information: socio-demographic variables (age, sex, length of time living in the area, educational level, occupation and type of health care system used); presence of indoor and outdoor pollutants (smoking, firewood, humidity, pets, pests, industry, construction sites); personal and family medical background (asthma, bronchitis, chronic cardiovascular and respiratory diseases); respiratory symptoms measured by standard questionnaires according to the participant's age group (infants, children and adults).

\section{Follow-up}

Visits were made to show participants how to keep a daily accurate record of variables over a period of six months. The correct use of this record was monitored by phone and personal visits by trained field staff. The record included questions on daily respiratory symptoms and clinic visits: hacking cough, coughing up phlegm, asphyxia, wheezing, use of inhalers, sneezing, increase in symptoms, outpatient visits, emergency room visits and hospitalization.

\section{Statistical analysis}

We conducted a descriptive analysis using a measure of proportion and central tendency. Incidence rates were calculated for each separate symptom (hacking cough, coughing up phlegm, asphyxia, wheezing, use of inhalers and sneez- 
ing) and for the sum of all symptoms (the "total symptoms" variable). The incidence rate ratio (IRR) was calculated as a measure of association using the area with high levels of PM10 pollution as a comparative reference category for the areas with low and medium levels of pollution collapsed into a single category. Due to the hierarchical nature of the associations studied, a multilevel mixed-effects Poisson analysis was conducted to adjust the effect of exposure to air pollution on other variables associated with symptom incidence. We used individual as the first level unit and neighborhood (proximity to cement industry and PM10 concentration area measurements) as the second level. We used the software Stata 10.0 (Stata Corp., College Station, USA) to perform the analysis.

\section{Ethics}

The study complied with the ethical principles of autonomy, confidentiality and beneficence in compliance with international guidelines for research involving human subjects. The study was approved by the Ethics Committee of the Fundación Oftalmológica de Santander - Clínica Carlos Ardila Lulle FOSCAL in Bucaramanga.

\section{Results}

We studied 770 people in areas with low (263), middle (259) and high (248) levels of air pollution, measured in PM10 concentrations, in 24 neighborhoods across the city of Bucaramanga between October 2009 and April 2010. Table 1 shows the main characteristics of the study population.

The participants were predominantly female (60.9\%), with an age range from one to 90 years old and with the following socioeconomic status: middle (74\%), low (14\%) and high (12\%).

The average number of people per household was 4.5 and the average number of rooms was three. Overcrowding was found to occur in $4.5 \%$ of homes. The predominant roof and floor material was tiles. Cigarette smoking (20.6\%) and aerosols (22.5\%) were the most common sources of indoor pollution. Domestic animals (dogs, cats, birds) and pests (cockroaches) were also commonly found in participant's homes. Some neighborhoods had potential outdoor sources of pollution, such as shoemaking and carpentry workshops near the houses (Table 2).

Approximately $34 \%$ of participants had a relative with a medical history of asthma. In the area with high levels of pollution, $11.6 \%$ of participants had relatives with chronic bronchitis, whereas in the other areas this proportion was around $7 \%$.

All participants had at least one chronic disease. The most common form of respiratory morbidity was asthma in both children (31.5\%) and adults (28\%). Chronic bronchitis (13\%) and chronic obstructive pulmonary disease (7\%) were also common in adults. Among the referred cardiovascular morbidities, arterial hypertension $(47 \%)$, diabetes $(27 \%)$, congestive cardiac failure $(15 \%)$ and cardiac arrhythmias (13\%) were the most commonly diagnosed in adult participants.

At the beginning of the study, the prevalence of respiratory sounds during the year leading up to the study was $66 \%$ in children under one year old, $80 \%$ in children between one and 14 years old and $43.7 \%$ in children over the age of 15 . Followup was carried out with $95 \%$ of the participants for a period of six months.

The incidence rate of total symptoms per 100participant-day was 46.7 across all areas with the following differences between zones: 17 in areas with high levels of pollution, 74.4 in areas with medium levels of pollution and 53.2 in areas with low levels of pollution. The IRR for each symptom was higher in areas with medium levels of pollution, except for the variables wheezing and use of inhalers that were higher in areas with high levels of pollution.

Some individual and neighborhood variables were also associated with the incidence of respiratory symptoms. Multivariate analysis using Poisson's multilevel approach showed that, after adjustment for these confounding variables, when compared to areas with high levels of pollution, the incidence of total symptoms was $60 \%$ and $74 \%$ lower in areas with medium $($ IRR $=0.40$; 95\%CI: $0.16-0.93$ ) and low levels of pollution (IRR $=0.26$; 95\%CI: 0.05-0.92) respectively.

Given that the effect of the areas with medium and low levels of pollution on respiratory symptoms was similar, we merged these two areas into one category to compare it with the high pollution area. Using this approach we found that the incidence of total symptoms was $51 \%$ lower in areas with medium to low levels of pollution (IRR $=0.49 ; 95 \%$ CI: 0.37-0.66). This finding is similar to that of the incidence of wheezing but not significant for the other symptoms evaluated (Table 3). Multilevel model analysis of total and individual symptoms also showed that living in a house with mold (fungal growth) or near to a construction site were consistently associated with higher incidence rates for most respiratory symptoms.

Living near to cement manufacturing plants was associated with an increased incidence of 
Sociodemographic characteristics of the study population. Bucaramanga, Colombia, 2009.

\begin{tabular}{|c|c|c|c|c|c|c|c|c|}
\hline \multirow[t]{2}{*}{ Variable } & \multicolumn{2}{|c|}{$\begin{array}{l}\text { Area with } \\
\text { high levels of } \\
\text { pollution } \\
(n=248)\end{array}$} & \multicolumn{2}{|c|}{$\begin{array}{l}\text { Area with } \\
\text { low levels of } \\
\text { pollution } \\
(n=263)\end{array}$} & \multicolumn{2}{|c|}{$\begin{array}{l}\text { Area with } \\
\text { medium levels } \\
\text { of pollution } \\
(n=259)\end{array}$} & \multicolumn{2}{|c|}{$\begin{array}{c}\text { Total } \\
(n=770)\end{array}$} \\
\hline & $\mathrm{n}$ & $\%$ & $\mathrm{n}$ & $\%$ & $\mathrm{n}$ & $\%$ & $\mathrm{n}$ & $\%$ \\
\hline \multicolumn{9}{|l|}{ Sex } \\
\hline Female & 150 & 61.2 & 167 & 63.5 & 152 & 58.0 & 469 & 60.9 \\
\hline Male & 98 & 40.0 & 96 & 36.5 & 107 & 40.8 & 301 & 39.1 \\
\hline Age [average] (years) & \multicolumn{2}{|c|}{46} & \multicolumn{2}{|c|}{49} & \multicolumn{2}{|c|}{56} & \multicolumn{2}{|c|}{52} \\
\hline \multicolumn{9}{|c|}{ Length of time resident in zone (months) } \\
\hline $6-12$ & 25 & 10.2 & 3 & 1.1 & 20 & 7.6 & 48 & 6.2 \\
\hline $13-18$ & 2 & 0.8 & 3 & 1.1 & 4 & 1.5 & 9 & 1.2 \\
\hline $19-24$ & 24 & 9.8 & 7 & 2.7 & 2 & 0.8 & 33 & 4.3 \\
\hline More than 24 & 196 & 80.0 & 250 & 95.1 & 231 & 88.2 & 267 & 87.9 \\
\hline \multicolumn{9}{|l|}{ Educational level } \\
\hline Kindergarten & 9 & 3.6 & 5 & 1.9 & 6 & 2.3 & 20 & 2.6 \\
\hline Elementary & 108 & 43.5 & 92 & 35.0 & 106 & 40.9 & 306 & 39.7 \\
\hline High School & 74 & 29.8 & 100 & 38.0 & 90 & 34.7 & 264 & 34.3 \\
\hline Associate-degree & 32 & 12.9 & 46 & 17.5 & 36 & 13.9 & 114 & 14.8 \\
\hline University & 5 & 2.0 & 8 & 3.0 & 1 & 0.4 & 14 & 1.8 \\
\hline None & 15 & 6.0 & 6 & 2.3 & 19 & 7.3 & 40 & 5.2 \\
\hline Not applicable & 5 & 2.0 & 6 & 2.3 & 1 & 0.4 & 12 & 1.6 \\
\hline \multicolumn{9}{|l|}{ Occupation } \\
\hline None & 24 & 9.7 & 1 & 0.4 & 12 & 4.6 & 37 & 4.8 \\
\hline Student & 42 & 16.9 & 7 & 2.7 & 43 & 16.6 & 92 & 11.9 \\
\hline House wife & 51 & 20.6 & 115 & 43.7 & 74 & 28.6 & 240 & 31.2 \\
\hline Employee & 10 & 4.0 & 6 & 2.3 & 13 & 5.0 & 29 & 3.8 \\
\hline Independent worker & 40 & 16.1 & 28 & 10.6 & 34 & 13.1 & 102 & 13.2 \\
\hline Retired & 18 & 7.3 & 16 & 6.1 & 32 & 12.4 & 66 & 8.6 \\
\hline Not applicable & 31 & 12.5 & 44 & 16.7 & 41 & 15.8 & 116 & 15.1 \\
\hline \multicolumn{9}{|l|}{ Health care system } \\
\hline Paid by own & 158 & 63.7 & 193 & 73.4 & 102 & 39.4 & 453 & 58.8 \\
\hline Paid by State & 75 & 30.2 & 58 & 22.1 & 142 & 54.8 & 275 & 35.7 \\
\hline No health care system & 15 & 6.0 & 12 & 2.6 & 14 & 5.4 & 41 & 5.3 \\
\hline
\end{tabular}

wheezing (IRR $=3.92 ; 95 \%$ CI: $1.19-12.89)$ and hospitalization $(\mathrm{IRR}=5.70 ; 95 \% \mathrm{CI}$ : 1.61-9.01). In contrast, the presence of birds as pets in houses seems to be protective for all type of symptoms, but not for hospitalization (IRR $=1.85 ; 95 \% \mathrm{CI}$ : 1.21-2.41).

\section{Discussion}

We found a positive association between the incidence of respiratory symptoms and exposure to daily mean concentrations of PM10 $>60 \mu \mathrm{g} / \mathrm{m}^{3}$ in people with chronic cardiovascular or respiratory disease.
Our study considered symptoms described by the individual and not according to a diagnosis made by health professionals. The fact that the symptoms an individual records may depend on their interest in the study or the care taken in filling out the forms could result in an information bias. However, our primary interest was to explore the association between levels of exposure to PM10 and perceived morbidity as a first manifestation of morbidity, contrary to diagnosed morbidity, which is subject to confounding bias due to factors associated with health care, such as access to medical services, that are frequently present in the Colombian health care system. Information bias due to lack 
Presence of indoor and outdoor pollutants. Bucaramanga, Colombia, 2009.

\begin{tabular}{|c|c|c|c|c|c|c|c|c|}
\hline \multirow[t]{2}{*}{ Variable } & \multicolumn{2}{|c|}{$\begin{array}{l}\text { Area with high } \\
\text { levels of pollution } \\
\qquad(n=248)\end{array}$} & \multicolumn{2}{|c|}{$\begin{array}{l}\text { Area with low } \\
\text { levels of pollution } \\
\qquad(n=263)\end{array}$} & \multicolumn{2}{|c|}{$\begin{array}{l}\text { Area with medium } \\
\text { levels of pollution } \\
\qquad(n=259)\end{array}$} & \multicolumn{2}{|c|}{$\begin{array}{c}\text { Total } \\
(\mathrm{n}=770)\end{array}$} \\
\hline & $\mathbf{n}$ & $\%$ & $\mathbf{n}$ & $\%$ & $\mathbf{n}$ & $\%$ & $\mathbf{n}$ & $\%$ \\
\hline \multicolumn{9}{|l|}{ Indoor pollutants } \\
\hline Cigarettes & 53 & 21.4 & 57 & 21.7 & 49 & 18.9 & 159 & 20.6 \\
\hline Tobacco & 1 & 0.4 & 4 & 1.5 & 0 & 0.0 & 5 & 0.6 \\
\hline Aerosols & 77 & 31.0 & 31 & 11.8 & 66 & 25.5 & 174 & 22.6 \\
\hline Firewood & 28 & 11.3 & 3 & 1.1 & 14 & 5.4 & 45 & 5.8 \\
\hline Carbon & 2 & 0.8 & 0 & 0.0 & 11 & 4.2 & 13 & 1.7 \\
\hline \multicolumn{9}{|l|}{ Other indoor pollutants } \\
\hline Fungus like formation & 31 & 12.5 & 8 & 3.0 & 29 & 11.2 & 68 & 8.8 \\
\hline Humidity & 64 & 25.8 & 32 & 12.2 & 44 & 17.0 & 140 & 18.2 \\
\hline Cockroaches & 132 & 53.2 & 112 & 42.6 & 148 & 57.1 & 392 & 50.9 \\
\hline Cats & 54 & 21.8 & 31 & 11.8 & 34 & 13.1 & 119 & 15.5 \\
\hline Dogs & 83 & 33.5 & 104 & 39.5 & 92 & 35.5 & 279 & 36.2 \\
\hline Birds & 64 & 25.8 & 70 & 26.6 & 82 & 31.7 & 216 & 28.1 \\
\hline Rodents & 68 & 27.4 & 92 & 35.0 & 49 & 18.9 & 209 & 27.1 \\
\hline \multicolumn{9}{|l|}{ Outdoor pollutants } \\
\hline Ovens & 181 & 73.0 & 42 & 16.0 & 109 & 42.1 & 332 & 43.1 \\
\hline Ornaments & 122 & 49.2 & 58 & 22.1 & 57 & 22.0 & 237 & 30.8 \\
\hline Shoemaker workshops & 154 & 62.1 & 184 & 70.0 & 125 & 48.3 & 463 & 60.1 \\
\hline Cement manufacturing plants & 50 & 20.2 & 55 & 20.9 & 6 & 2.3 & 111 & 14.4 \\
\hline Dump & 59 & 23.8 & 61 & 23.2 & 52 & 20.1 & 172 & 22.3 \\
\hline Carpentry workshops & 164 & 66.1 & 117 & 44.5 & 116 & 44.8 & 397 & 51.6 \\
\hline High concentration of traffic & 204 & 82.3 & 97 & 36.9 & 197 & 76.1 & 498 & 64.7 \\
\hline Construction sites & 106 & 42.7 & 30 & 11.4 & 99 & 38.2 & 235 & 30.5 \\
\hline
\end{tabular}

of recording or poor memory was controlled by phone checks and personal visits to participants in order to remind them to accurately fill out the daily record.

The measurement of air pollution was another potential source of bias since it was not possible to place more than two monitoring stations in each study area. However, the air quality monitoring network in Bucaramanga, which was responsible for measurement, followed World Health Organization (WHO) criteria in the selection of monitoring sites and complied with the Environmental Protection Agency (EPA) guidelines for the installation and operation of outdoor equipment. A quality check of the measurements resulting from the use of manual monitors was carried out by comparing final results of PM10 weight per filter in two different reference laboratories in the city.

The inclusion criterion for patients was selfreported chronic respiratory or cardiovascular disease confirmed by clinical documents pro- vided by the participants at enrollment. As these were not cross-checked with patients' medical histories available in health care centers, this may result in a selection bias in the case of individuals that did not report or remember their actual morbidity. However, certain studies 15 have shown that memory bias is less likely to occur in cases of chronic disease in adults or catastrophic events in children, and in all cases the participant and the relatives taking care of him/her were aware of the chronic disease.

To control confounding bias in the survey of basic variables, personal, household and neighborhood variables were collected at enrollment and a simple stratified and multivariate analysis of other variables also associated with the incidence of symptoms was conducted. The results of this analysis also suggest other indoor pollution variables, such as fungal formation in homes, which are highly associated with the incidence of respiratory symptoms. A recent study in the same areas of the city showed that some types of 
Multilevel analysis of outdoor air pollution area effect on incidence of respiratory symptoms. Bucaramanga, Colombia, 2009-2010.

\begin{tabular}{|c|c|c|c|c|c|c|}
\hline \multirow[t]{2}{*}{ Variable } & \multicolumn{2}{|c|}{ General symptoms } & \multicolumn{2}{|c|}{ Wheezing } & \multicolumn{2}{|c|}{ Hacking cough } \\
\hline & IRR & $95 \% \mathrm{Cl}$ & IRR & $95 \% \mathrm{Cl}$ & IRR & $95 \% \mathrm{Cl}$ \\
\hline Level of pollution * & 0.49 & $0.37-0.66$ & 0.52 & $0.37-0.73$ & 0.42 & $0.05-1.03$ \\
\hline Aerosols & 0.96 & $0.94-0.99$ & 0.76 & $0.69-0.83$ & 0.98 & $0.93-1.03$ \\
\hline Fungus like formation & 1.33 & $1.29-1.37$ & 1.56 & $1.40-1.72$ & 1.33 & $1.24-1.43$ \\
\hline Birds & 0.84 & $0.83-0.86$ & 0.76 & $0.71-0.82$ & 0.85 & $0.81-0.88$ \\
\hline Ornaments & 0.92 & $0.89-0.94$ & 0.77 & $0.70-0.85$ & 0.95 & $0.90-1.00$ \\
\hline Cement manufacturing plants & 1.36 & $0.70-2.62$ & 3.92 & $1.19-12.89$ & 1.50 & $0.61-3.67$ \\
\hline Dump & 0.71 & $0.69-0.93$ & 0.72 & $0.66-0.79$ & 0.69 & $0.66-0.73$ \\
\hline \multirow[t]{3}{*}{ Construction sites } & 1.24 & $1.21-1.27$ & 1.12 & $1.03-1.22$ & 1.19 & $1.13-1.25$ \\
\hline & \multicolumn{2}{|c|}{ Coughing up phlegm } & \multicolumn{2}{|c|}{ Asphyxia } & \multicolumn{2}{|c|}{ Symptoms increase } \\
\hline & IRR & $95 \% \mathrm{Cl}$ & IRR & $95 \% \mathrm{Cl}$ & IRR & $95 \% \mathrm{Cl}$ \\
\hline Level of pollution * & 0.33 & $0.02-1.15$ & 0.71 & $0.29-3.70$ & 0.92 & $0.23-3.66$ \\
\hline Aerosols & 0.92 & $0.86-0.97$ & 0.74 & $0.70-0.79$ & 5.43 & $3.98-7.40$ \\
\hline Fungus like formation & 1.73 & $1.62-1.85$ & 0.84 & 076-0.92 & 4.96 & $3.44-7.14$ \\
\hline Birds & 0.87 & $0.82-0.91$ & 0.65 & $0.62-0.69$ & 0.56 & $0.40-0.78$ \\
\hline Ornaments & 0.84 & $0.79-0.90$ & 0.81 & $0.76-0.87$ & 1.49 & $1.06-2.11$ \\
\hline Cement manufacturing plants & 1.93 & $0.26-4.61$ & 1.38 & $0.28-3.50$ & 0.95 & $0.16-3.95$ \\
\hline Dump & 0.72 & $0.68-0.77$ & 0.70 & $0.66-0.75$ & 0.59 & $0.40-0.86$ \\
\hline \multirow[t]{3}{*}{ Construction sites } & 1.10 & $1.0-1.16$ & 1.24 & $1.17-1.31$ & 0.48 & $0.32-0.70$ \\
\hline & \multicolumn{2}{|c|}{ Outpatient visits } & \multicolumn{2}{|c|}{ Emergency room visits } & \multicolumn{2}{|c|}{ Hospitalization } \\
\hline & IRR & $95 \% \mathrm{Cl}$ & IRR & $95 \% \mathrm{Cl}$ & IRR & $95 \% \mathrm{Cl}$ \\
\hline Level of pollution * & 0.50 & $0.14-1.94$ & 0.67 & $0.13-1.34$ & 1.36 & $0.37-5.00$ \\
\hline Aerosols & 1.60 & $1.37-1.87$ & 1.10 & $0.81-1.51$ & 1.79 & $1.36-2.37$ \\
\hline Fungus like formation & 1.10 & $0.87-1.40$ & 0.73 & $0.43-1.24$ & 0.80 & $0.46-1.38$ \\
\hline Birds & 0.84 & $0.72-0.98$ & 0.80 & $0.59-1.07$ & 1.85 & $1.21-2.41$ \\
\hline Ornaments & 0.96 & $0.80-1.14$ & 0.85 & $0.61-1.17$ & 1.85 & $1.29-2.67$ \\
\hline Cement manufacturing plants & 0.97 & $0.23-4.30$ & 1.71 & $0.21-3.66$ & 5.70 & $1.61-9.01$ \\
\hline Dump & 1.02 & $0.86-1.20$ & 1.81 & $0.6-1.15$ & 1.40 & $1.39-2.70$ \\
\hline Construction sites & 0.82 & $0.68-0.98$ & 1.43 & $1.06-1.91$ & 2.90 & 2.14-3.92 \\
\hline
\end{tabular}

IRR: incidence rate ratio (adjusted); $95 \% \mathrm{Cl}: 95 \%$ confidence interval.

* Middle-low pollution levels compared to high pollution levels (reference category).

fungus and mites are associated with respiratory asthma-like symptoms in children under the age of seven 16 .

Our findings are consistent with others reported in a variety of countries. An epidemiological survey among Japanese schoolchildren showed that the prevalence of asthmatic symptoms, chest congestion and phlegm was significantly correlated with PM10 levels 17 where annual average PM10 concentrations in urban areas next to roads, urban areas near to roads and suburban settings were $45.1-52.7 \mu \mathrm{g} / \mathrm{m}^{3}$, 36.5$43.3 \mu \mathrm{g} / \mathrm{m}^{3}$ and $27.8-32.4 \mu \mathrm{g} / \mathrm{m}^{3}$ respectively.
Moon et al. 18 recently found similar associations among children in Korea but these were site-dependent for each pollutant.

In Sidney, Morgan et al. 19 conducted a time series analysis of associations between daily hospital admissions and external contaminants. This study revealed that an increase in daily maximum concentration of particles at a certain time was associated with increased admissions for chronic obstructive pulmonary disease $(3.01 \%$; $95 \% \mathrm{CI}$ : 0.38-6.52). Associations between air pollutants and respiratory symptoms, low birth weight and lung cancer have also been shown in Sri Lanka 20 . 
In Latin-America, studies on the relation between PM10 concentrations and mortality have been carried out in Brazil, Chile and Mexico. In São Paulo, studies showed that an increase in PM10 concentrations equivalent to $10 \mu \mathrm{g} / \mathrm{m}^{3}$ was associated with an increase of $3 \%$ in daily mortality in people aged 65 years and over 21 . The same increase in PM10 concentrations resulted in an increase of $0.8 \%$ in daily mortality $(95 \% \mathrm{CI}$ : $0.6-1.2$ ) in Chile 22 and $0.5 \%$ (95\%CI: $0.3-0.7$ ) in Mexico 23.

Many years ago in Mexico, Romieu et al. ${ }^{24}$ reported an increase of $4 \%$ in respiratory symptoms in asthmatic children and a decrease of $0.35 \%$ in lung function associated with an increase in PM10 concentrations of $10 \mu \mathrm{g} / \mathrm{m}^{3}$. These results are consistent with others in the USA 25 . In a similar recent study in Brazil, Moura et al. 26 reported an increase of $6.7 \%$ in pediatric visits of children under the age of two associated with PM10 concentrations.

Our findings suggest the existence of effectmodifying variables associated with co-morbidity, such us cardiac congestive failure and diabetes, indicating different effects on respiratory symptoms depending on the type of morbidity. Kan et al. 27 found season, sex, age, and education were modifiers of the effects of outdoor air pollution on daily mortality in Shanghai, China: however, these researchers used information sources that did not take into account morbidity background. In Colombia, although seasons are not well defined due to the country's location in the tropics, dry and wet periods are identifiable and their effect should be explored in further analysis. Schikowski et al. 28 also found an independent association between long-term exposure to air pollution and impaired respiratory health and increased cardiovascular mortality.

For most of the population in developed and developing countries, the effect of exposure to
PM10 on human health occurs when exposure is regular and consistent. Chronic exposure to these particles increases the risk of cardiovascular and respiratory disease and lung cancer 29. In response to this situation and to protect public health in USA, the EPA has been implementing the National Ambient Air Quality Standards (NAAQS) 13 since 1970. These standards have been updated and are currently adopted by a number of countries, including Colombia, to protect air quality. Currently the 24-hour PM10 standard is $150 \mu \mathrm{g} / \mathrm{m} 3$ and the annual mean standard is $50 \mu \mathrm{g} / \mathrm{m}^{3}$. Our findings reveal that these adjusted levels for Colombia are higher than the threshold limit for incidence of respiratory symptoms in susceptible populations. This population is the first to be affected by air pollution and therefore should be the first to be protected through the imposition of adequate standard limits.

In 1987 theWHO produced guidelines 30 in order to reduce the sanitary effects of air pollution. The current guidelines 31 , applicable throughout the world based on scientific evidence, fix the 24-

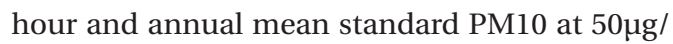
$\mathrm{m}^{3}$ and $20 \mu \mathrm{g} / \mathrm{m}^{3}$ respectively. These limits are more conservative than those suggested by the NAAQS and are more consistent with our findings. These levels were also proposed to reduce greenhouse effect gases and global warming.

We recommend the adoption of the WHO guidelines for air quality and the inclusion of environmental counseling into educational programs directed at patients with chronic respiratory or cardiovascular disease regardless of age, in Bucaramanga and Colombia as a whole. Future research should be aimed at determining the impact of reductions in PM10 concentrations 32 on the quality of life of populations and at refining the measurement and analysis methodologies to enable the investigation of the effect of smaller particles such as PM2.5 and other pollutants 33 . 


\section{Resumen}

Se realizó un estudio de cohorte para investigar si la exposición a tres niveles diferentes de contaminación atmosférica extra-domiciliaria está asociada a la incidencia de síntomas respiratorios en una población con enfermedad cardiovascular o respiratoria crónica. Se siguieron por un periodo de seis meses a 756 participantes con morbilidad, usando calendario diario de síntomas y visitas personales. Los síntomas que tuvieron mayores tasas de incidencia fueron el estornudo y la tos seca. El análisis multivariado mostró que la zona de mayor contaminación estaba asociada con un $60 \%$ y $74 \%$ más de sintomas respiratorios, comparada con la zona de contaminación media y baja, respectivamente. Estos resultados sugieren que los efectos negativos a nivel respiratorios son vistos con exposiciones por encima de $60 \mu \mathrm{g} / \mathrm{m}^{3}$ de material particulado PM10 en esta población.

Signos y Síntomas Respiratorios; Enfermedad Crónica; Contaminación del Aire; Población

\section{Contributors}

L. A. Rodriguez-Villamizar participated in the epidemiologic study design, supervision of field work, data analysis and drafting of this manuscript. H. Castro-Ortiz assisted in the study design, field work, data analysis and assisted in the drafting of the manuscript. J. J. ReySerrano participated in the study design, assisted with data analysis and the revision of this manuscript.

\section{Acknowledgments}

The authors are grateful to Astrid Berena Herrera López and Manuel Antonio Campos for their quality field work and to Helver Reyes, Technical Coordinator of air pollution research of the Columbian Ministry of Environment, Housing and Territorial Development, for technical recommendations and improvements to the project.

\section{References}

1. Vargas MF. La contaminación ambiental como factor determinante de la salud. Rev Esp Salud Pública $2005 ; 79: 117-27$.

2. Guilbert JJ. The World Health Report 2002: reducing risks, promoting healthy life. Educ Health (Abingdon) 2003; 16:230.

3. Zeller M, Giroud M, Royer C, Benatru I, Besancenot JP, Rochette L, et al. Pollution de l'air et pathologie athérothrombotique cardiaque et cérébrale: données épidémiologiques. Presse Med 2006; 35(10 Pt 2):1517-22.

4. Brunekreef B, Forsberg B. Epidemiological evidence of effects of coarse airborne particles on health. Eur Respir J 2005; 26:309-18.

5. Sun Q, Hong X, Wold LE. Cardiovascular effects of ambient particulate air pollution exposure. Circulation 2010; 121:2755-65.

6. Perez L, Rapp R, Künzli N. The year of the lung: outdoor air pollution and lung health. Swiss Med Wkly 2010; 140:w13129.
7. Rosales-Castillo JA, Torres-Meza VM, Olaiz-Fernandez G, Borja-Aburto VH. Los efectos agudos de la contaminación del aire en la salud de la población: evidencias de estudios epidemiológicos. Salud Pública Méx 2001; 43:544-55.

8. Pelucchi C, Negri E, Gallus S, Boffetta P, Tramacere I, La Vecchia C. Long-term particulate matter exposure and mortality: a review of European epidemiological studies. BMC Public Health 2009; 9:453.

9. Chen Y, Craig L, Krewski D. Air quality risk assessment and management. J Toxicol Environ Health A 2008; 71:24-39.

10. Sacks JD, Stanek LW, Luben TJ, Johns DO, Buckley BJ, Brown JS, et al. Particulate matter-induced health effects: who is susceptible? Environ Health Perspect 2010; 119:446-54.

11. Bernstein JA, Alexis N, Barnes C, Bernstein IL, Nel A, Peden D, et al. Health effects of air pollution. J Allergy Clin Immunol 2004; 114:1116-23. 
12. Ministry of Housing Environment and Territorial Development. Resolution 0601: air quality standards for Colombia. Bogotá: Ministry of Housing Environment and Territorial Development; 2006.

13. Environmental Protection Agency. National Ambient Air Quality Standards (NAAQS) 2006. http:// www.epa.gov/air/criteria.html (accessed on 09/ Dec/2010).

14. Villamizar LAR, Lopez ABH, Ortiz HC, Velazquez JN, Cala LMV. Incidencia de síntomas respiratorios y su asociación con contaminación atmosférica en preescolares: un análisis multinivel. Cad Saúde Pública 2010; 26:1411-8.

15. Rajmil L, Fernandez E, Gispert R, Rue M, Glutting JP, Plasencia A, et al. Influence of proxy respondents in children's health interview surveys. J Epidemiol Community Health 1999; 53:38-42.

16. Herrera A, Rodríguez L, Niederbacher J. Contaminación biológica intradomiciliaria y su relación con síntomas respiratorios indicativos de asma bronquial en preescolares de Bucaramanga, Colombia. Biomedica 2011; 31:357-71.

17. Nakai S, Nitta H, Maeda K. Respiratory health associated with exposure to automobile exhaust. II. Personal NO2 exposure levels according to distance from the roadside. J Expo Anal Environ Epidemiol 1995; 5:125-36.

18. Moon JS, Kim YS, Kim JH, Son BS, Kim DS, Yang W. Respiratory health effects among schoolchildren and their relationship to air pollutants in Korea. Int J Environ Health Res 2009; 19:31-48.

19. Morgan G, Corbett S, Wlodarczyk J. Air pollution and hospital admissions in Sydney, Australia, 1990 to 1994. Am J Public Health 1998; 88:1761-6.

20. Nandasena YL, Wickremasinghe AR, Sathiakumar N. Air pollution and health in Sri Lanka: a review of epidemiologic studies. BMC Public Health 2010; 10:300.

21. Saldiva PH, Pope 3rd CA, Schwartz J, Dockery DW, Lichtenfels AJ, Salge JM, et al. Air pollution and mortality in elderly people: a time-series study in São Paulo, Brazil. Arch Environ Health 1995; 50:159-63.

22. Ostro BD, Eskeland GS, Sanchez JM, Feyzioglu T. Air pollution and health effects: a study of medical visits among children in Santiago, Chile. Environ Health Perspect 1999; 107:69-73.

23. Borja-Aburto VH, Loomis DP, Bangdiwala SI, Shy CM, Rascon-Pacheco RA. Ozone, suspended particulates, and daily mortality in Mexico City. Am J Epidemiol 1997; 145:258-68.
24. Romieu I, Carreon T, Lopez L, Palazuelos E, Rios C, Manuel Y, et al. Environmental urban lead exposure and blood lead levels in children of Mexico City. Environ Health Perspect 1995; 103:1036-40.

25. Pope 3rd CA, Thun MJ, Namboodiri MM, Dockery DW, Evans JS, Speizer FE, et al. Particulate air pollution as a predictor of mortality in a prospective study of U.S. adults. Am J Respir Crit Care Med 1995; 151(3 Pt 1):669-74.

26. Moura M, Junger WL, Mendonça GAS, Leon AP. Air quality and emergency pediatric care for symptoms of bronchial obstruction categorized by age bracket in Rio de Janeiro, Brazil. Cad Saúde Pública 2009; 25:635-44.

27. Kan H, London SJ, Chen G, Zhang Y, Song G, Zhao $\mathrm{N}$, et al. Season, sex, age, and education as modifiers of the effects of outdoor air pollution on daily mortality in Shanghai, China: the Public Health and Air Pollution in Asia (PAPA) Study. Environ Health Perspect 2008; 116:1183-8.

28. Schikowski T, Sugiri D, Ranft U, Gehring U, Heinrich J, Wichmann HE, et al. Does respiratory health contribute to the effects of long-term air pollution exposure on cardiovascular mortality? Respir Res 2007; 8:20.

29. World Health Organization Regional Office for Europe. Air quality guidelines for Europe. 2nd Ed. Copenhagen: World Health Organization Regional Office for Europe; 2000. (WHO Regional Publications, European Series, 91).

30. Ewers U. WHO guidelines for air quality in Europe. Offentl Gesundheitswes 1988; 50:626-9.

31. World Health Organization. Air quality guidelines for particular matter, ozone, nitrogen dioxide and sulfure dioxide. Global update 2005. Summary of risk assessment. Geneva: World Health Organization; 2006.

32. Giles LV, Barn P, Kunzli N, Romieu I, Mittleman MA, van Eeden S, et al. From good intentions to proven interventions: effectiveness of actions to reduce the health impacts of air pollution. Environ Health Perspect 2010; 119:29-36.

33. Nitta H, Yamazaki S, Omori T, Sato T. An introduction to epidemiologic and statistical methods useful in environmental epidemiology. J Epidemiol 2010; $20: 177-84$.

Submitted on 24/Apr/2011

Final version resubmitted on 16/Nov/2011

Approved on 12/Dec/2011 